\title{
Understanding Residential Relocation Choices in Coastal Cities in the Face of Climate Change
}

\author{
Haiyun Wang ${ }^{1}$ (D), Glen Searle ${ }^{2}$ (D), Siqin Wang ${ }^{1}$ (D) ${ }^{\text {a }}$, Yan Liu ${ }^{1}$ (D) \\ ${ }^{1}$ School of Earth and Environmental Sciences, University of Queensland, ${ }^{2}$ School of Earth and Environmental Sciences, University of Queensland; School of \\ Architecture, Design and Planning, University of Sydney \\ Keywords: climate change, relocation choices, flooding, sea level rise, housing preference, dwelling types \\ https://doi.org/10.32866/001c.23722
}

\section{Findings}

Climate change poses risks of inundation to low-lying coastal cities and may cause residential relocation and change in housing demand. Taking the City of Gold Coast in Queensland, Australia as a case study, this paper reports on a survey that investigates the potential responses of residents living in the coastal city to flood risks and how the responses may relate to their socio-economic status. Through a combined online and mail-based survey, our data show that people's perceptions of flooding have an important impact on their relocation choices. Their perceptions and relocation choices are associated with their socio-economic background. Furthermore, residents' preferences of dwelling types appear to be affected by the level of flood risks we hypothesise in the survey. The findings from this study provide empirical evidence for future residential zoning and urban development.

\section{Questions}

Sea level rise as the largest scale calamity that is related to climate change increases flood risks in coastal areas. Existing studies indicate that flooding was the most common term used by people to describe their perception of the impact of climate change (Taylor, de Bruin, and Dessai 2014; Whitmarsh 2009). We hypothesise that people living in coastal areas with different socioeconomic backgrounds may respond to flood risks differently when considering their residential relocation and housing choices. We explore the influence of flooding as an indicator of climate change on people's relocation choices and analyse how their responses may vary based on their demographic and socio-economic backgrounds. Our research questions are:

1. How important is flooding being perceived as a factor affecting people's relocation choices?

2. Are there differences in people's relocation choices in response to flood risks when socio-economic situations are considered?

3. What types of dwellings do people prefer in areas with different levels of flood risk? 


\section{Methods}

We used raw data collected through a questionnaire survey conducted in the City of Gold Coast in Queensland, Australia. The questionnaire consisted of three sections. The first section asked respondents about their sociodemographic information including age, income, education, occupation, marital status, and tenure type. Section two consisted of questions to explore the importance of factors affecting their relocation choices, including potential flood risk, neighbourhood characteristics, housing features, and ease of access to amenities and jobs. The last section consisted of questions related to flooding, and how this may impact on their relocation choices. Both Likert scale and multiple-choice questions were used.

We collected data using both web-based and mail-based surveys in selected suburbs in the Gold Coast. Amongst a total of 93 suburbs in the Gold Coast, 40 suburbs have established their community groups on Facebook to connect local residents. Some suburbs have established more than one community group, and some suburbs have established a joint community group with neighbouring suburbs. To implement our survey, we approached all these community groups, 31 of which agreed to post our questionnaire on their Facebook page for their members to complete online. For the other 53 suburbs without a community group on Facebook, we randomly selected four suburbs using the online Random Choice Generator tool and sent our survey questionnaire to residents in these four suburbs via the unaddressed mail service provided by Australia Post (2021).

The online survey was conducted from $13^{\text {th }}$ July to $8^{\text {th }}$ August 2020 . Two thousand copies of survey questionnaires were posted to residents in the four suburbs from $7^{\text {th }}$ to $11^{\text {th }}$ September 2020. A total of 247 responses were received with 224 from the online survey and 23 from the mail-based survey.

The majority of respondents were middle-aged, well educated, middle to high income, homeowners, married, and living in a house. The composition of the survey respondents is similar to that of the overall population composition as evidenced in the latest census (Australian Bureau of Statistics 2016). However, the relatively small sample size and the fact that the majority of respondents $(90.7 \%)$ were obtained from the online survey indicate some potential bias in our data which may not be a fully representative of the total population and excluded respondents who cannot access the Internet (Fan and Yan 2010; Fricker et al. 2005; National Telecommunications and Information Administration 2004), therefore, further research would be needed to validate the analytical results presented in this study. 


\begin{tabular}{lcccc}
\hline & Building features & Flooding & Convenience & Neighbourhood characteristics \\
\hline Average score & 3.88 & 3.47 & 3.19 & 3.13 \\
Std. deviation & 1.03 & 1.46 & 1.26 & 1.25 \\
\hline
\end{tabular}

\section{Findings}

\section{The importance of flooding as a factor influencing relocation choices}

To measure the influence of climate change on people's relocation choices, we used flooding as a factor to reflect the consequences of climate change. We asked participants to score the factors listed in the survey from one (not at all important) to five (very important). Besides flooding, other factors were related to neighbourhood characteristics, housing features, and convenience (ease of access to amenities and jobs). Table 1 shows that respondents were most concerned about housing features such as price, dwelling type, noise, view, and building performance. Flooding was next in importance when people choose to relocate. Compared to building features and flooding, convenience and neighbourhood characteristics are less important. Nevertheless, we can conclude that flooding, as one of the consequences of climate change, plays an important role in people's relocation choices.

Concerning the socio-economic characteristics of respondents who considered flooding as an important or very important factor affecting their relocation, Table 2 shows that this applied mostly to respondents in high-income households. Other features of the respondents who gave high importance to flooding showed they were mainly composed of managers, administrators, and professionals (MAPs), students, married, middle age, homeowners, and the well-educated.

\section{Relocation choices in response to impending flood risk}

To understand people's relocation choices in relation to flooding, we provided a hypothetical scenario that the area people currently live in will be flooded within the next ten years. Under this scenario, participants were offered three options to respond to the scenario: 1) "move to a safer place" (Move); 2) "stay because I cannot afford the relocation cost" (Stay1); or 3) "stay because I can afford to rebuild" (Stay2). Figure 1 illustrates the proportion of respondents choosing to Move, Stay 1, or Stay 2 by their socio-demographic characteristics and income levels; these three cohorts of respondents are represented using dark blue, blue, and light blue colours, respectively. The results show that people with a higher education level tend to choose Move more than those with a lower education level. In contrast to homeowners, a larger proportion of tenants choose to Move. Besides students, MAPs and the unemployed are more likely to move to a safer area than those in other occupation groups. There is 
Table 2. The percentage of respondents who consider flooding as an important or very important factor influencing their relocation choices

\begin{tabular}{|c|c|c|c|c|}
\hline \multirow[b]{2}{*}{ Categories } & \multirow[b]{2}{*}{ Groups } & \multirow[b]{2}{*}{ Number of respondents } & \multicolumn{2}{|c|}{ Important or Very important } \\
\hline & & & Number of respondents & Percentage (\%) \\
\hline \multirow[t]{5}{*}{ Household income } & $\$ 0-999$ & 48 & 24 & 50.00 \\
\hline & $\$ 1000-1499$ & 59 & 32 & 54.24 \\
\hline & $\$ 1500-1999$ & 54 & 24 & 44.44 \\
\hline & $>=\$ 2000$ & 86 & 55 & 63.95 \\
\hline & Total & 247 & 135 & 54.66 \\
\hline \multirow[t]{6}{*}{ Occupation } & MAPs $^{1}$ & 139 & 80 & 57.55 \\
\hline & Labourers & 9 & 2 & 22.22 \\
\hline & Students & 15 & 10 & 66.67 \\
\hline & Unemployed & 11 & 3 & 27.27 \\
\hline & Others & 73 & 40 & 54.79 \\
\hline & Total & 247 & 135 & 54.66 \\
\hline \multirow[t]{3}{*}{ Marital status } & Single & 74 & 31 & 41.89 \\
\hline & Married & 173 & 104 & 60.12 \\
\hline & Total & 247 & 135 & 54.66 \\
\hline \multirow[t]{5}{*}{ Age } & $<25$ & 18 & 8 & 44.44 \\
\hline & $25-40$ & 72 & 41 & 56.94 \\
\hline & $40-65$ & 128 & 72 & 56.25 \\
\hline & $>65$ & 29 & 14 & 48.28 \\
\hline & Total & 247 & 135 & 54.66 \\
\hline \multirow[t]{3}{*}{ Tenure type } & Rent & 50 & 20 & 40.00 \\
\hline & Own & 171 & 105 & 61.40 \\
\hline & Total & 221 & $125^{2}$ & 56.56 \\
\hline \multirow[t]{4}{*}{ Education } & Below Bachelor's degree & 89 & 43 & 48.31 \\
\hline & Bachelor's degree & 79 & 44 & 55.70 \\
\hline & Above Bachelor's degree & 79 & 48 & 60.76 \\
\hline & Total & 247 & 135 & 54.66 \\
\hline
\end{tabular}

Note:

${ }^{1}$ MAPs: managers, administrators, and professionals

${ }^{2}$ The total number of respondents who considered flooding as an important or very important factor is $135 ; 10$ of those respondents did not provide tenure type

also a slightly higher portion of people choosing to move as household income increases, with the exception being the middle-income group $(\$ 1,500-1,999)$. Furthermore, of those who choose to stay in place, it is understandable that those who choose Stay 2 are mostly high-income households, MAPs, married, and homeowners as they are more likely to afford to rebuild after a flood (Figure 1).

\section{Preference of dwelling types in different flood risk areas}

Assuming that the level of resistance of a building to flood is primarily affected by its building height, with the higher in building height the more resistant the building to flood, we asked respondents to choose their preferred dwelling types in different flood risk areas. Figure 2 shows a decreasing trend in the 


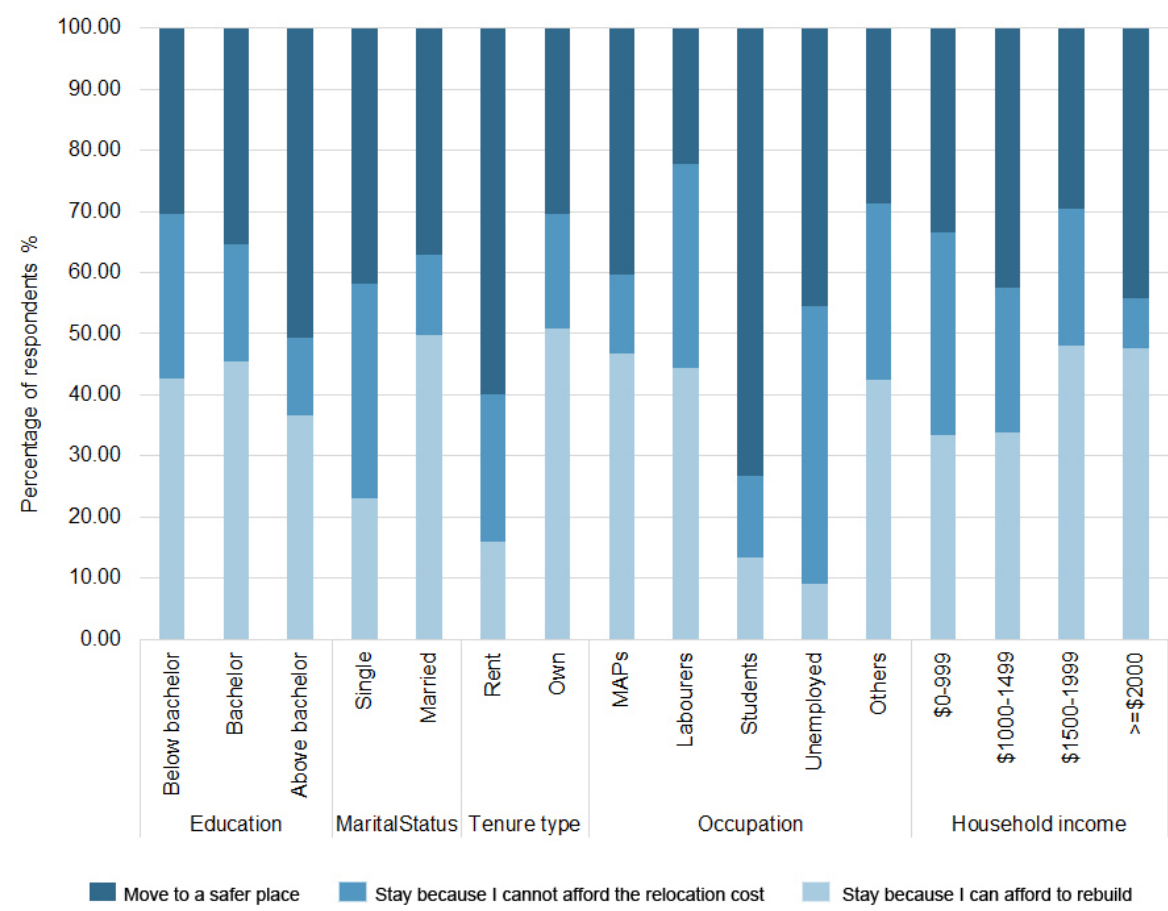

Figure 1. The distribution of relocation choices responding to flood risks among different population groups

number of respondents who wish to live in a house on the ground as the flood risk increases. This trend is inverse to the popularity of houses on stilts and the decision to not live in the risk area. These two options were more commonly selected by the survey respondents when the level of flood risk increases. These several trends show a shift in popularity from houses on the ground to houses on stilts and deciding not to live in the area as the flood risk increases. In medium flood risk areas, participants who wished to live in houses on stilts closely rivalled those who chose grounded houses. When the flood risk increased to high, both stilted houses and vacating the risk area overtook grounded houses in popularity. There was also an increase in respondents who wished to move to multi-storey apartments with the advent of increased flood risk, especially to units above five levels. Despite this, such housing is significantly less popular than individual (detached) housing, independent of the flood risk. The shift in housing preferences demonstrates the respondent's evaluation of the significance of flood risk in their decision to live in differing types of dwellings.

\section{Acknowledgements}

This study is funded by Australian Research Council Discovery Grant [DP170104235]. 


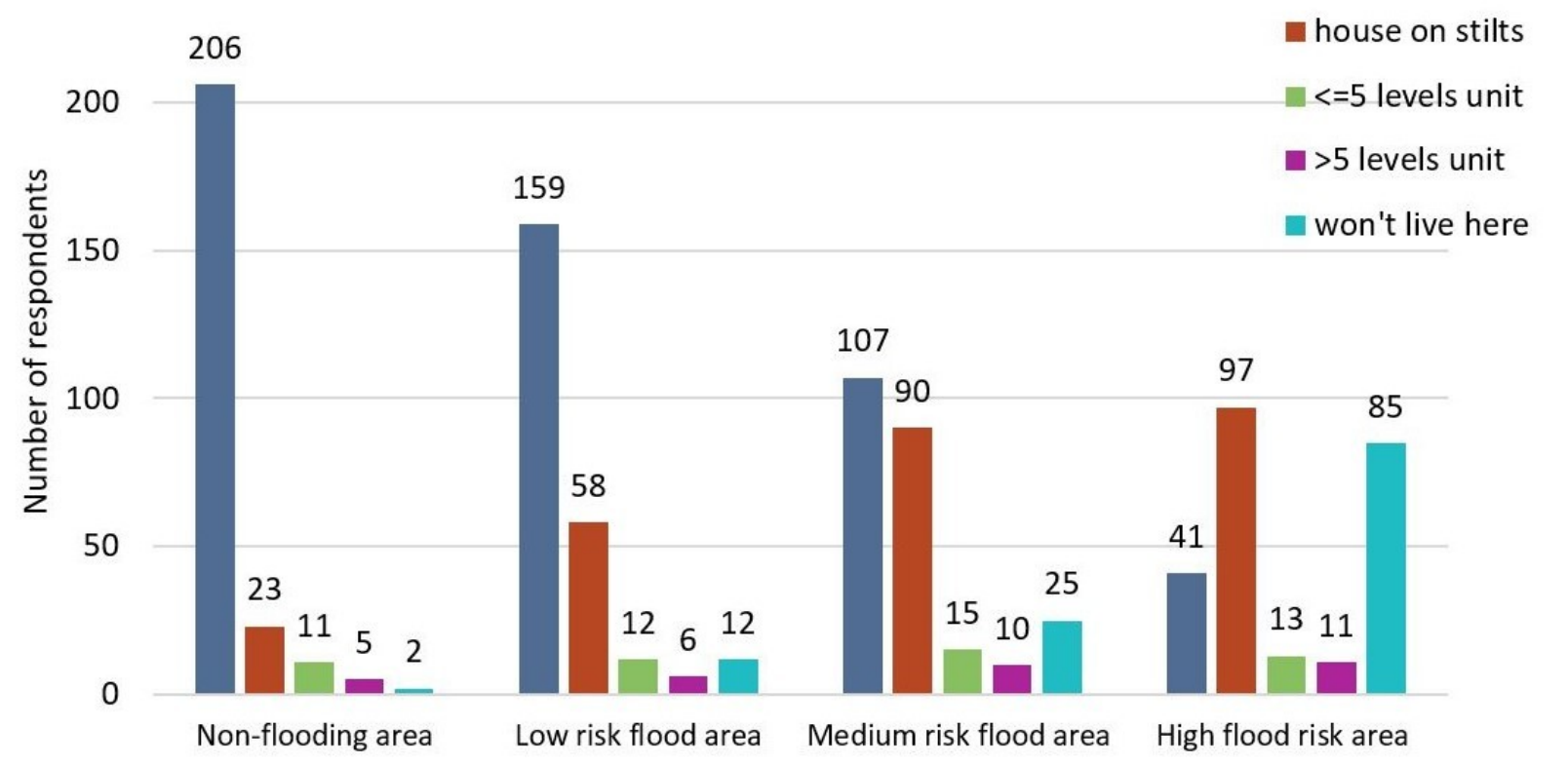

Figure 2. Preference of dwelling types in different flood risk areas by survey respondents 


\section{REFERENCES}

Australia Post. 2021. “Letterbox Advertising Connecting Is as Easy as 1,2,3.” 2021.

https://auspost.com.au/content/dam/auspost_corp/media/documents/Letterbox-AdvertisingStep-By-Step-Guide.pdf.

Australian Bureau of Statistics. 2016. "2016 Census Community Profiles.” https://quickstats.censusdata.abs.gov.au/census_services/getproduct/census/2016/ communityprofile/LGA33430?opendocument.

Fan, Weimiao, and Zheng Yan. 2010. "Factors Affecting Response Rates of the Web Survey: A Systematic Review." Computers in Human Behavior 26 (2): 132-39. https://doi.org/10.1016/ j.chb.2009.10.015.

Fricker, S., M. Galesic, R. Tourangeau, and T. Yan. 2005. "An Experimental Comparison of Web and Telephone Surveys." Public Opinion Quarterly 69 (3): 370-92. https://doi.org/10.1093/poq/ nfi027.

National Telecommunications and Information Administration. 2004. A Nation Online: Entering the Broadband Age. Washington, DC: U.S. Department of Commerce.

Taylor, Andrea, Wändi Bruine de Bruin, and Suraje Dessai. 2014. "Climate Change Beliefs and Perceptions of Weather-Related Changes in the United Kingdom." Risk Analysis 34 (11): 1995-2004. https://doi.org/10.1111/risa.12234.

Whitmarsh, Lorraine. 2009. "What's in a Name? Commonalities and Differences in Public Understanding of 'Climate Change' and 'Global Warming." Public Understanding of Science 18 (4): 401-20. https://doi.org/10.1177/0963662506073088. 
Appendix: Survey questions

1. Age of respondent

$\square$ Under 25 $\square$ 25-40 $\square$ 40-65 $\square$ above 65

2. What is your highest education qualification? (Please tick one only)

$\square$ Below or equal to high school diploma/certificate

$\square$ Bachelor's degree

$\square$ Equal or above postgraduate diploma/certificate

3. Marital status

$\square$ Single $\square$ Married

4. Are you a dependant in your household?

$\square$ Yes (Please go to question 7)

$\square$ No

5. Do you rent or own your current home?

$\square$ Rent $\square$ Own

6. What is your total household income per week?

$\square \$ 0-\$ 999 \square \$ 1,000-\$ 1,499 \square \$ 1,500-\$ 1,999 \square \$ 2,000$ or above

7. What is your occupation?

$\square$ Professionals, managers, and administrators

$\square$ Labourers $\square$ students $\square$ unemployed $\square$ others

8. Please rate the importance of the factors below that you may have considered when you either bought or rented your current home $(1=$ not at all important, $2=$ slightly important, 3 =moderately important, $4=$ =important, and $5=$ =very important)

9. If your suburb were to be flooded in the next 10 years, where would you choose to live?

$\square$ I would move to a safe place

$\square$ I would stay because I couldn't afford the cost of relocation

$\square$ I would stay because I could afford to rebuild or repair after the flood 
Table 3

\begin{tabular}{|c|c|c|c|c|c|c|}
\hline & & $\begin{array}{l}\text { Not at all } \\
\text { important }\end{array}$ & $\begin{array}{l}\text { Slightly } \\
\text { important }\end{array}$ & $\begin{array}{l}\text { Moderately } \\
\text { important }\end{array}$ & Important & $\begin{array}{l}\text { Very } \\
\text { important }\end{array}$ \\
\hline \multicolumn{2}{|l|}{ Flooding } & 1 & 2 & 3 & 4 & 5 \\
\hline \multirow{3}{*}{ Convenience } & $\begin{array}{l}\text { Access to amenities } \\
\text { (shops, cafes, parks/ } \\
\text { open space, etc.) }\end{array}$ & 1 & 2 & 3 & 4 & 5 \\
\hline & $\begin{array}{l}\text { Access to public } \\
\text { transport }\end{array}$ & 1 & 2 & 3 & 4 & 5 \\
\hline & Access to jobs & 1 & 2 & 3 & 4 & 5 \\
\hline \multirow{5}{*}{$\begin{array}{l}\text { Building } \\
\text { Features }\end{array}$} & Price & 1 & 2 & 3 & 4 & 5 \\
\hline & Noise & 1 & 2 & 3 & 4 & 5 \\
\hline & View & 1 & 2 & 3 & 4 & 5 \\
\hline & $\begin{array}{l}\text { Building performance } \\
\text { (quality, energy } \\
\text { efficiency, thermal } \\
\text { comfort, etc.) }\end{array}$ & 1 & 2 & 3 & 4 & 5 \\
\hline & $\begin{array}{l}\text { Dwelling types (house, } \\
\text { townhouse, unit, etc.) }\end{array}$ & 1 & 2 & 3 & 4 & 5 \\
\hline \multirow{5}{*}{$\begin{array}{l}\text { Neighbourhood } \\
\text { Characteristics }\end{array}$} & Crime rate & 1 & 2 & 3 & 4 & 5 \\
\hline & Quality schools & 1 & 2 & 3 & 4 & 5 \\
\hline & $\begin{array}{l}\text { Ethnic composition of } \\
\text { the community }\end{array}$ & 1 & 2 & 3 & 4 & 5 \\
\hline & $\begin{array}{l}\text { Socioeconomic status of } \\
\text { neighbours }\end{array}$ & 1 & 2 & 3 & 4 & 5 \\
\hline & Environmental greening & 1 & 2 & 3 & 4 & 5 \\
\hline
\end{tabular}

10. In a non-flooding area, please select below your preferred dwelling type

Multiple dwellings (no more than 5 storeys) $\square$ High level dwellings ( 5 storeys or more) $\square$ House on stilts $\square$ House on ground $\square$ Won't live here

11. In a 1-in-500-year flood (low flood risk) area, please select below your preferred dwelling type

Multiple dwellings (no more than 5 storeys) $\square$ High level dwellings ( 5 storeys or more)

$\square$ House on stilts $\square$ House on ground $\square$ Won't live here

12. In a 1-in-100-year flood (medium flood risk) area, please select below your preferred dwelling type

Multiple dwellings (no more than 5 storeys) $\square$ High level dwellings ( 5 storeys or more)

$\square$ House on stilts $\square$ House on ground $\square$ Won't live here 
13. In a 1-in-20-year flood (high flood risk) area, please select below your preferred dwelling type

$\square$ Multiple dwellings (no more than 5 storeys) $\square$ High level dwellings ( 5 storeys or more)

$\square$ House on stilts $\square$ House on ground $\square$ Won't live here 